\title{
Factors Influencing Participation of Informal Sector Workers in Formal Social Security Schemes in Dodoma City, Tanzania
}

\author{
Zacharia S. Masanyiwa*, Erick S. Mosha, Sarah F. Mamboya \\ Institute of Rural Development Planning, Dodoma, Tanzania \\ Email: ^zmasanyiwa@irdp.ac.tz
}

How to cite this paper: Masanyiwa, Z. S., Mosha, E. S., \& Mamboya, S. F. (2020). Factors Influencing Participation of Informal Sector Workers in Formal Social Security Schemes in Dodoma City, Tanzania. Open Journal of Social Sciences, 8, 229-242. https://doi.org/10.4236/jss.2020.86020

Received: January 17, 2019

Accepted: June 12, 2020

Published: June 15, 2020

Copyright ( 2020 by author(s) and Scientific Research Publishing Inc. This work is licensed under the Creative Commons Attribution International License (CC BY 4.0).

http://creativecommons.org/licenses/by/4.0/

\begin{abstract}
Social security is widely recognized as a basic human right. However, in most developing countries, majority of the population, especially in the informal sector is not covered by existing social security schemes. This paper examines factors influencing informal sector workers' participation in the formal social security schemes in Dodoma City, Tanzania. The specific objectives of the paper are to 1) identify the type of economic activities performed by informal sector workers, and 2) analyze the determinants of informal sector workers participation in formal social security schemes. The paper draws on survey data collected from 184 informal sector workers' through structured interviews and documentary review, and analyzed for descriptive statistics, chi-square test and binary logistic regression. The findings revealed that a relatively higher proportion female (56\%) than male (44\%) were involved in the informal economic activities, mainly food vending (32\%), selling cereals $(20 \%)$ and petty shops (18\%). Only about one quarter of the informal sector workers (23\%) were members of the formal social security schemes, and a substantial proportion was involved in the relatively informal schemes, such as village community banks (67\%), savings and credit cooperative societies (59\%) and rotating saving and credit associations (6\%) as alternatives to formal social security schemes. The factors that significantly influenced informal sector workers' participation in the formal social security schemes were sex, contribution rates, monthly income, capital and nature of the business. Given the low participation of informal sector workers in the formal social security schemes, it is recommended that deliberate efforts should be put in place to educate informal sector workers on the importance of the social security schemes, including the benefits offered by the schemes. Similarly, social security schemes should set their monthly contribution rates at a level that is affordable to informal sector workers given their relatively low incomes, and
\end{abstract}


design benefits packages that fit the need of the informal sector workers.

\section{Keywords}

Social Security, Informal Sector, Participation, Social Security Schemes, Tanzania

\section{Introduction}

Social security is a basic human right and fundamental means for creating social position, thereby helping to ensure social peace and social inclusion (ILO, 2002). Defined by Holzmann and Jorgensen, 2000, as cited by Maduga, 2015, as public interventions to assist individuals, households and communities better manage risk, and provide support to the critically poor, social security is critical because every human being is vulnerable to risks and uncertainties with respect to income as a means of life sustenance. To contain these risks, everyone needs some form of social security guaranteed by the family, community and the society as a whole. According to the International Labour Organisation (ILO, 2018), social security systems provide for basic income in cases of unemployment, illness and injury, old age and retirement, invalidity, family responsibilities such as pregnancy and childcare, and loss of the family breadwinner. Such socio-economic risks and uncertainties in human life form the basis for the need of social security. In the world today, social security schemes are recognized by governments in both the developed and developing countries as a realistic strategy to fight poverty and accelerate socio-economic progress (Kyengo, 2010; ILO, 2018). By providing health care, income security and social services, social security enhances productivity and contributes to the dignity and full realization of the individual (ILO, 2018).

While the need for social protection is widely recognized, this fundamental human right remains unfulfilled for the majority of world's population. Old-age economic security is a considerable problem for such populations and providing adequate and secure income flows in the future is a formidable challenge (Agravat \& Kaplelach, 2017). According to ILO (2014), only 27 percent of the global population enjoys access to social security systems, whereas 73 percent are either covered partially or not at all. Non-coverage is greatest in Sub-Saharan Africa and South Asia, where more than 90 percent of the population is not covered at all (Maduga, 2015; ILO, 2018). In these developing countries, non-coverage is high, because the existing social security systems mostly in the form of contributory schemes were designed specifically to benefit workers in the formal sector, hence, tend to exclude the majority of the working population, who are employed in the informal economy. This is because more than 90 percent of the workforce in those countries is informally employed (Kyengo, 2010; Dorfman, 2015). A major contributing factor towards decreasing and low levels of social security coverage in these regions is the trend towards greater informalization or 
flexibility in labour market conditions, which in essence leave majority of workers outside the realm of social protection systems (Keizi, 2006; Kyengo, 2010). Agravat and Kaplelach (2017) explain that in countries with high levels of informal employment, social security coverage rates often remain legally restricted to those, frequently a small minority, working in the formal labour market.

By definition, informal sector workers are generally those with low incomes or self-employed, working in very small (unregistered) companies or the household sector, often on a part-time basis, in industries such as agriculture, construction and services (Hu \& Stewart, 2009). The informal workforce is not only unregulated and untaxed, but also unprotected. Compared to workers in the formal sector who normally join either mandatory or voluntary pension systems, or both, those in the informal sector are typically not covered well (in many cases not at all) by modern, structured pension systems. They do not have access to pension plans organised or run by employers, may lack official registration papers or other documents which could help the relevant authorities target them for other schemes, may change job frequently and often live and work in rural areas which financial infrastructure is poor or non-existent (Hu \& Stewart, 2009; Agravat \& Kaplelach, 2017). In Tanzania, the percentage of the labour force covered by the formal security schemes is estimated to be less than 10 per cent of the population (Maduga, 2015).

In addressing this problem, various social security reforms have been implemented around the world in recent decades highlighting the need for improving social security coverage for informal sector workers (Dorfman, 2015). Both the international community and national governments have realized the increasing importance and urgency of extending the social security system to cover the informal sector by including workers in the national social security schemes on a similar basis as the formal sector (Kyengo, 2010; Dorfman, 2015). In Tanzania, the National Social Security Policy was introduced in 2003 to expand the coverage of social security to different segments of the population including informal sector workers. Amongst others, the policy established the Social Security Regulatory Authority (SSRA), which sets the agenda and implements the social security reform programme with a focus on extension of coverage, including informal sector workers (URT, 2003). Since then, various reforms have been undertaken to improve provision of social security services in the country, including the formulation of laws that enforce all the formal social security schemes to include informal sector workers on similar basis as the formal sector workers, and provision of improved social security benefit packages that suit the informal sector workers like maternity, sickness, employment injury, survivors and funeral benefits (SSRA, 2013).

However, despite these efforts, social security schemes in developing countries still face various challenges, including the low participation of informal sector workers in the formal social security schemes. In Tanzania, for instance, social security covers three distinctive branches: basic protection which involves government intervention in the form of social assistance to the destitute and those 
who could pass the means test; the mandatory contributory schemes; and the privately administered supplementary personal or employer-based arrangements. All these are voluntary in nature and mostly suit individuals with sufficient disposable income unless they are solely funded by the employer (Maduga, 2015). Before the recent merging of the social security schemes into two schemes (National Social Security Fund and Public Service Social Security Fund) in 2018, there were seven social security schemes namely; National Social Security Fund (NSSF), Parastatal Pension Fund (PPF), LAPF Pension Fund (LAPF), Public Service Pension Fund (PSPF), Government Employees Provident Fund (GEPF), National Health Insurance Fund (NHIF) and Zanzibar Social Security Fund (ZSSF).

However, total coverage was less than 10 percent of the economic working population in which the coverage for informal sector workers was less than 2 percent of the covered population (Dungumaro, 2012; SSRA, 2013; Maduga, 2015). At the same time, the increase in informal sector activities in the country has led to the formation of various forms of social security like Rotating Saving and Credit Associations (ROSCAS), Village Community Banks (VICOBA) and Savings and Credit cooperative Societies (SACCOS), social networks and groups which are more preferred by the informal sector workers compared to the formalized social security schemes (Dungumaro, 2012). This raises concerns on the factors influencing the informal sector worker's participation in the formal social security schemes.

Despite the vast scholarship on informal sector and social security in other sub-Saharan African countries, less has been documented in the academic literature about the factors influencing informal sector workers' participation in formal social security schemes in Tanzania. For instance, a study by Kyengo (2010) in Nairobi, Kenya established that only a small extent of the informal sector workers was covered by retirement benefit/pension schemes. In the Tamale metropolis of Ghana, Adzawla et al. (2015) revealed that the elderly, the single, the highly educated, highly depended and higher income workers have a higher probability of contributing to the informal pension schemes. In another study, Kayitare (2016) found that the key obstacles hindering the pension coverage of workers in informal sector in Rwanda include; legal roadblocks, low and irregular incomes, lack of awareness, benefit design and structure.

The few studies on the subject in Tanzania have focused on different aspects, including Olivier et al. (2012) who focus on lack of education, low incomes and the nature of enterprises in informal sector are barriers that make informal sector workers fail to join the available social security schemes in Tanzania. Maduga (2015) explores the factors that restrict the widening of social security coverage in Tanzania. Overall, these studies focus on few variables like contribution rates, awareness and nature of informal businesses. However, there are other factors that can influence informal sector workers participation in formal social security schemes in a specific context which have received less attention in previous studies. This paper contributes to this gap in the scholarly literature by examining 
the factors influencing participation of informal sector workers in the social security schemes in Dodoma City, Tanzania. The specific objectives of the study are twofold: 1) to identify the type of economic activities performed by informal sector workers, and 2) to analyze the determinants of informal sector workers' participation in formal social security schemes. The remainder of the paper is structured as follows. The next section describes the study area and methodology used in this study, including the design, sample size and sampling procedures, data types, sources, collection methods and analysis techniques. Then, we present and discuss the findings of the study. In the last section, we draw the key conclusions and recommendations emerging from the study.

\section{Study Area and Methodology}

The data presented in this paper derive from a study that was conducted at $\mathrm{Vi}$ wandani and Majengo wards in Dodoma City between March and May 2018. The wards were purposively selected because are located within the central business district in the city, hence, are among the highly populated wards with presence of several economic activities, including the informal ones such as food vending, tailoring/sowing, motor cycle transport, retail shops, hair cutting and dressing saloons, and mobile money transaction agents. The two wards are also home to the two big markets in the city: Sabasaba market in Viwandani and Majengo market in Majengo, which provide market for various informal economic activities.

A cross-sectional design, which involved collecting data once at a point in time was adopted in this study. Primary data were collected directly from informal sector workers through structured interviews using a structured questionnaire with both closed and open-ended questions. The questionnaire was designed to solicit information about socio-demographic characteristics, the type of economic activities practiced by informal sector workers, size of the activities, duration of involvement in the activities, and the factors influencing informal sector workers participation in the social security schemes. The questionnaire was chosen as important tool of collecting data from respondents due to its cost-effectiveness and strength in capturing empirical data in both formal and informal settings (Kothari \& Carg, 2014). To enhance validity of the findings, the questionnaire was pretested with selected informal sector workers and improved accordingly based on the issues that emerged from this exercise. Secondary data were collected through documentary review of reports relating to informal sector workers participation in social security schemes, records from the ward offices, Dodoma City Council and LAPF Pension Fund.

The target population of the study was all informal sector workers engaged in various economic activities in the two wards, which was estimated to be more than 2000. In line with the definition of informal sector workers described earlier (Hu \& Stewart, 2009), in this study, informal sector workers were generally defined as those self-employed as petty traders, food vendors, hawkers and re- 
lated occupations, often earning little incomes. The sample size was computed using the following sample estimation formula:

$$
n=\frac{z \propto / 2 \cdot P(1-P)}{\lambda^{2}}
$$

where by $n=$ Sample size

$P=$ percentage of informal sector workers.

$Z \propto / 2$ is the critical value (1.96), $\lambda^{2}=$ maximum error; since $P$ is not known for the study population, its value was assumed to be $50 \%$ as it ensures maximum sample size. Assuming a confidence interval of $95 \%$ for the estimated population proportion, maximum error of 5\%, a sample size of 184 informal sector workers was selected. Convenience sampling technique was used to select respondents who were available and willing to participate in the interviews at the time of the survey.

The collected data were sorted, coded, edited and analyzed by using Statistical Package for Social Sciences (SPSS version 21). Descriptive statistics such as means, frequencies and, percentage were computed for most of the variables. Chi square test was used to test association between various variables. Binary logistic regression was used to analyze the determinants for informal sector workers participation in the formal social security schemes. The binary logistic regression model was expressed as:

$$
\ln \left(\frac{p}{1-p}\right)=\alpha+\sum_{i=1}^{m} \beta_{i} x_{i}+e
$$

where: $\alpha$ and $\beta_{i}$ are parameters

$p=$ Proportion of informal sector workers participation in formal social security schemes

$x_{i}=$ Determinants for participation in formal social security schemes

$$
e=\text { Error term }
$$

Consequently, the explanatory variables specified were:

$X_{1}=$ Age (years)

$X_{2}=\operatorname{Sex}(1=$ if male, $0=$ if female $)$

$X_{3}=$ Education level ( 1 if educated, 0 if not educated)

$X_{4}=$ Nature of business ( 1 if permanent, 0 if temporary)

$X_{5}=$ Duration of involvement in economic activity (years)

$X_{6}=$ Income (TZS)

$X_{7}=$ Amount contributed (TZS)

$X_{8}=$ Benefit offered ( 1 if easy to access, 0 if otherwise)

$X_{9}=$ Capital (TZS)

$\mu=$ Error term

\section{Results and Discussion}

\subsection{Socio-Demographic Characteristics of Respondents}

This study enrolled 184 informal sector workers. The characteristics of respon- 
dents described in this study included sex, age, marital status, education level and monthly incomes of the respondents. More than half of the respondents (56\%) were females, suggesting that more women than men are mostly involved in the informal economic activities. The findings reflect what has been observed in other studies that women are more concentrated in the less formal, less visible and more vulnerable employment areas without any social protection instruments (Dungumaro, 2012). The findings in Table 1 show that majority of the respondents $(60.3 \%)$, with a significantly $(p=0.048)$ larger proportion of males (65.5\%) than females (56.3\%) were aged between 18 and 35 years and few (9.3\%) were above 45 years ( $4.9 \%$ males vs $12.6 \%$ females). These results suggest that youth were more likely to be engaged in the informal economic activities than other age groups, partly because the former are the most active labour force at their career peak. Similar observations were reported by Kyengo (2010) in Nairobi County in Kenya that youth participate more in the informal economic activities compared to adults and elders, but also engage less in the social security schemes compared to the adults and elders.

More than half of the respondents were married (57.1\%), just over a quarter were singles $(26.6 \%)$ and few were either divorced (8.7\%) or widows/widowers (7.6\%). Significantly $(p=0.003)$ larger proportion of female respondents $(60.2 \%)$ than their male counterparts (53.1\%) were married. Over half of the respondents had primary education (54.9\%) with significantly $(p=0.04)$ higher proportion of female respondents (61.2\%) than male respondents (46.9\%). Slightly above one

Table 1. Socio-demographic characteristics of respondents by sex $(n=184)$.

\begin{tabular}{|c|c|c|c|c|c|}
\hline Variable & Categories & Male & Female & Total & Chi-square values \\
\hline \multirow{3}{*}{ Age (years) } & $18-35$ & $53(65.5)$ & $58(56.3)$ & $111(60.3)$ & \multirow{3}{*}{$\begin{array}{l}X^{2}=0.517 \\
p=0.048\end{array}$} \\
\hline & $36-45$ & $24(29.6)$ & $32(31.1)$ & $56(30.4)$ & \\
\hline & Above 45 & $4(4.9)$ & $13(12.6)$ & $17(9.3)$ & \\
\hline \multirow{4}{*}{ Marital status } & Single & $21(25.9)$ & $28(27.2)$ & 49 (26.6) & \multirow{4}{*}{$\begin{array}{l}X^{2}=0.91 \\
p=0.003\end{array}$} \\
\hline & Married & $43(53.1)$ & $62(60.2)$ & $105(57.1)$ & \\
\hline & Divorced & $9(11.1)$ & $7(6.8)$ & $16(8.7)$ & \\
\hline & Widows/widower & $8(9.9)$ & $6(5.8)$ & $14(7.6)$ & \\
\hline \multirow[t]{4}{*}{ Education level } & No formal & $15(18.5)$ & $10(9.7)$ & $25(13.6)$ & \multirow{4}{*}{$\begin{aligned} X^{2} & =0.61 \\
p & =0.04\end{aligned}$} \\
\hline & Primary & $38(46.9)$ & $63(61.2)$ & $101(54.9)$ & \\
\hline & Secondary & $16(19.8)$ & $22(21.3)$ & $38(20.7)$ & \\
\hline & Tertiary & $12(14.8)$ & $8(7.8)$ & $20(10.8)$ & \\
\hline \multirow{4}{*}{$\begin{array}{l}\text { Monthly income } \\
\text { (TZS) }\end{array}$} & Less than 100,000 & $18(22.1)$ & $24(23.3)$ & $42(22.8)$ & \multirow{4}{*}{$\begin{array}{l}X^{2}=0.66 \\
p=0.019\end{array}$} \\
\hline & $100,000-300,000$ & $55(67.9)$ & $75(72.8)$ & $130(70.7)$ & \\
\hline & Above 300,000 & $8(10)$ & $4(3.9)$ & $12(6.5)$ & \\
\hline & Average income & 197,358 & 166,495 & 180,082 & \\
\hline
\end{tabular}

Figures in brackets are percents. 
fifth had secondary education (20.7\%) whereas only just over one tenth had tertiary education (10.8\%). This could suggest that a large proportion of the labour force in the informal sector does not have higher education attainment required to participate in the formal economic activities. In Kenya, Agravat and Kaplelach (2017) found that $41 \%$ of the informal sector workers had primary education, implying that the respondents had low level of education, which could perhaps have had a bearing on their participation in social security schemes.

The average monthly income of the respondents was TZS 180,082 whereas male respondents earned relatively higher (TZS 197,358) than their female counterparts (TZS 166,495). The majority of respondents reported monthly incomes of between TZS 100,000 and $300,000(70.7 \%)$, with significantly ( $p=$ $0.019)$ more female $(72.8 \%)$ than male $(67.9 \%)$ respondents in this category. Close to a quarter (22.8\%) reported earning less than TZS 100,000 and only $6.5 \%$ had monthly incomes above TZS 300,000. These findings suggest most of the informal sector workers had generally lower incomes, which could possibly not allow collection of mandatory contributions by social security schemes, thus, hindering their participation in the formal social security schemes. Dorfman (2015) explains that contributory schemes have proved useful for workers with consistent wage incomes, but large informal labour forces have generally resulted in very loo coverages for both workers and retirees.

\subsection{Nature of Economic Activities Performed by Informal Sector Workers}

In this study, nature of economic activities performed by the respondents was operationalised in terms of type of the activity, size in terms of capital and duration the respondent had been involved in the activity. The results in Table 2 indicate that food vending was the most common activity performed by about one third respondents (31.5\%) and transport services was the least (3.3\%). Comparatively, higher proportions of female respondents were engaged in food vending (44.7\%) and petty trade (20.4\%) than their male counterparts who accounted for $14.8 \%$ and $16.0 \%$, respectively, in these activities. Conversely, more male respondents were involved in cereal selling $(32.1 \%)$, retail shops $(17.4 \%)$ and transport services $(7.4 \%)$ compared to $10.7 \%, 11.6 \%$ and $0.0 \%$, respectively, of the female respondents. This shows that gender had an influence on the type of economic activities performed by men and women in the informal sector. Keizi (2006) found that the informal economy accounts for a higher share of total urban employment for women than the case for men, because the former can more easily combine work with their other burden of family responsibility, and partly for other related reasons, such as gender discrimination encountered in the formal sector. The findings also corroborate those by Adzawla et al. (2015) in Ghana where $36 \%$ of the informal sector workers were involved into trading (mostly selling of consumables), which partly explains the urbanisation context of many cities in developing countries where the major informal activity would be trading. 
Table 2. Economic activities performed by the respondents by sex $(\mathrm{n}=184)$.

\begin{tabular}{cccc}
\hline Economic activities & Male & Female & Total \\
\hline Petty traders & $13(16.0)$ & $21(20.4)$ & $34(18.4)$ \\
Food vendors & $12(14.8)$ & $46(44.7)$ & $58(31.5)$ \\
Cereal sellers & $26(32.1)$ & $11(10.7)$ & $37(20.1)$ \\
Retailers & $14(17.4)$ & $12(11.6)$ & $26(14.2)$ \\
Mobile money transaction agents & $7(8.6)$ & $9(8.7)$ & $16(8.7)$ \\
Transport services & $6(7.4)$ & $0(0.0)$ & $6(3.3)$ \\
Others & $3(3.7)$ & $4(3.9)$ & $7(3.8)$ \\
\hline
\end{tabular}

Figures in brackets are percents. $X^{2}=0.71, p=0.089$.

The average capital of the informal economic activities was TZS 287,673, with male respondents reporting relatively higher capital (TZS 489,370) than their female counterparts (TZS 129,058). Close to half of the respondents $(46.7 \%)$ had capital of less than TZS 100,000 , with a significantly $(p=0.041)$ larger proportion of female $(63.1 \%)$ than male $(25.9 \%)$ respondents in this category. Contrastingly, whereas most male respondents (60.5\%) reported capital sizes of between TZS 100,000 and 500,000, less than one third of the female respondents (31.1\%) reported this category (Table 3 ). This shows that most female informal sector workers had low capital investments in the economic activities they were engaged in. In Rwanda, Kayitare (2016) found that size of the informal economic activities is one of the obstacles hindering pension coverage to informal sector workers in the developing countries.

With regard to duration of involvement in the economic activities, it was found that about two thirds of the respondents had been involved in their activities for more than twelve months (64.1\%) and only few (4.3\%) for less than three months. Just over one fifth had been involved in these economic activities for between seven and twelve months (22.3\%). There was no significant difference $(p=0.89)$ between male and female respondents on the duration of involvement in economic activities (Table 4). This indicates that the majority of the informal sector workers had experience in these activities. As Olivier et al. (2012) argue, having experience helps the informal sector worker to understand and analyze risks in the business and increases the likelihood of engaging in the social security schemes.

\subsection{Informal Sector Workers' Participation in Social Security Schemes}

Participation in social security schemes was operationalized by asking respondents whether were members of any of the social security schemes, formal or informal. The results show that only about a quarter of the respondents were members of the formal social security schemes (23.4\%) whereas more than three quarters were not $(76.6 \%)$. A significantly $(p=0.04)$ higher proportion of male (33.3\%) than female (15.5\%) respondents were members of the social security 
Table 3. Capital economic activity performed by the respondents $(n=184)$.

\begin{tabular}{cccc}
\hline Amount of capital (TZS) & Male & Female & Total \\
\hline Less than 100,000 & $21(25.9)$ & $65(63.1)$ & $86(46.7)$ \\
$100,000-500,000$ & $49(60.5)$ & $32(31.1)$ & $81(44.1)$ \\
Above 500,000 & $11(13.6)$ & $6(5.8)$ & $17(9.2)$ \\
Average capital & 489,370 & 129,058 & 287,673 \\
\hline
\end{tabular}

Figures in brackets are percents. $X^{2}=0.617, p=0.041$.

Table 4. Business experience of the respondents by sex $(n=184)$.

\begin{tabular}{cccc}
\hline Business experience & Male & Female & Total \\
\hline Less than 3 months & $2(2.5)$ & $6(5.8)$ & $8(4.3)$ \\
$3-6$ months & $9(11.1)$ & $8(7.8)$ & $17(9.2)$ \\
$7-12$ months & $18(22.2)$ & $23(22.3)$ & $41(22.3)$ \\
More than 12 months & $52(64.2)$ & $66(64.1)$ & $118(64.1)$ \\
\hline
\end{tabular}

Figures in brackets are percents. $X^{2}=0.68, p=0.89$.

schemes (Table 5). This shows that most of the informal sector workers were not covered by the formal social security schemes, thus, confirming previous studies elsewhere (Kayitare, 2016; Kyengo, 2010; Agravat \& Kaplelach, 2017), although Adzawla et al. 2015 found higher proportion (54\%) in Ghana. As Dorfman (2015) explains, there could be several explanations for such low coverage level, including the low and intermittent sources of income, and the misalignment of wage-based contributory schemes with the characteristics and needs of informal sector workers.

This partly explains why more than two thirds of respondents $(67.3 \%)$ were members of VICOBA ( $50.5 \%$ females and $16.8 \%$ males) and more than half (59.2\%) were SACCOS members (34.2\% males vs. $25.0 \%$ females) as shown in Table 5. These findings reflect observations by Dungumaro (2012) that informal sector workers engage more in ROSCAS, VICOBA and SACCOS compared to the formalized social security schemes. This is because of the nature of the activities they are engaged in, and accessibility to these organizations is also simpler to them compared to the formal social security schemes. Olivier et al. (2012) also hold similar views that informal sector workers engage more in these organizations as it takes long time to access benefits of formal social security schemes compared to these organizations.

\subsection{Determinants for Informal Sector Workers' Participation in Formal Social Security Schemes}

The binary logistic regression results in Table 6 indicate that $62.5 \%$ of variations in participation in formal social security schemes was explained by the explanatory variables included in the model $\left(\mathrm{R}^{2}=0.625\right)$. It was found that informal sector workers' participation in formal social security schemes was significantly 
Table 5. Participation of respondents in social security schemes $(n=184)$.

\begin{tabular}{cccccc}
\hline Variable & Participation & Male & Female & Total & Chi-square values \\
\hline $\begin{array}{c}\text { Membership in } \\
\text { formal social }\end{array}$ & Member & $27(33.3)$ & $16(15.5)$ & $43(23.4)$ & $X^{2}=0.81$ \\
security schemes & Non-member & $54(66.7)$ & $87(84.5)$ & $141(76.6)$ & $p=0.04$ \\
$\begin{array}{c}\text { Membership in } \\
\text { other forms of } \\
\text { social protection }\end{array}$ & SACCOS & $63(34.2)$ & $46(25.0)$ & $109(59.2)$ & \\
& VICOBA & $31(16.8)$ & $93(50.5)$ & $124(67.3)$ & $X^{2}=0.92$, \\
& ROSCAS & $0(0.0)$ & $11(5.9)$ & $11(5.9)$ & \\
\hline
\end{tabular}

Figures in brackets are percents.

Table 6. Determinants of informal sector workers' participation in the formal social security schemes $(\mathrm{n}=184)$.

\begin{tabular}{ccccc}
\hline Explanatory variable & B & S.E. & Wald & $P$-value \\
\hline Age (years) & 0.002 & 0.008 & 0.238 & $0.812^{\mathrm{NS}}$ \\
Sex $(1=$ male) & 0.131 & 0.103 & 1.274 & $0.026^{* *}$ \\
Duration of involvement in business (years) & -0.028 & 0.060 & -0.474 & $0.637^{\mathrm{NS}}$ \\
Education Level (1 = educated) & -0.065 & 4.34 & -0.872 & $0.529^{\mathrm{NS}}$ \\
Amount contributed (TZS) & 0.568 & 18.02 & 0.268 & $0.000^{* *}$ \\
Nature of business (1 = permanent) & -0.35 & 3.23 & -0.359 & $0.003^{* *}$ \\
Monthly income (TZS) & 0.739 & 15.69 & 1.327 & $0.000^{* * *}$ \\
Capital (TZS) & 0.683 & 6.16 & 1.201 & $0.032^{* *}$ \\
Constant & 0.397 & 0.570 & 0.698 & $0.031^{* *}$ \\
\hline
\end{tabular}

$\mathrm{R}^{2}=0.625, \mathrm{~F}=83.3, P<0.05 .{ }^{* *}$ Significant at $5 \%,{ }^{* *}$ Significant at $1 \%$, ${ }^{\mathrm{NS}}$ Not significant.

influenced by sex, nature of business, amount contributed, monthly income and capital. It was revealed that sex of the respondent had positive significant ( $p=$ $0.026)$ relationship with participation in the formal social security schemes. Male respondents were more likely to participate in the social security schemes by $13 \%$ compared to female respondents. The possible explanation for this was that most of male respondents were operating high capital economic activities and had higher monthly incomes compared to female respondents. Also, more female than male respondents participated in the other forms of social protection, which increased their possibilities of not participating in the formal social security schemes.

The nature of business had significant, but negative relationship $(p=0.003)$ with participation in the formal social security schemes. Respondents with permanent business places were less likely to participate in the formal social security schemes by $35 \%$ than those with temporary business places. This could be partly due to the fact that majority of the respondents had no permanent places for their economic activities as most of them involved shifting from one market side to another. Because of the nature of their activities, it was established that mobility enabled informal sector workers to increase their sales and earnings com- 
pared to being located at permanent area. Thus, it was possible that the mobile workers generated higher incomes to enable them to participate in the social security more than those with permanent places. Further, respondents with permanent places had higher operating costs in terms of rent, taxes and other market levies, which reduced their profits making it difficult for them to participate in the formal social security schemes. These findings are contrary to what was reported by Maduga that nature of business has a positive influence on participation to social security schemes, suggesting that some of the determinants could be context specific (Maduga, 2015).

Further, the amount contributed was positively and significantly $(p=0.000)$ associated with participation in formal social security schemes. An increase in one unit of amount contributed was likely to increase the probability of participation of informal sector workers in the formal social security schemes by $56.8 \%$. The reason for this is that, the amount to be contributed is fixed at TZS 20,000 for informal workers. However, these findings are contrary to Maduga who found that amount contributed has negative relationship with participation to formal social security schemes (Maduga, 2015).

The results also show that respondent's monthly income had positive significant $(p=0.000)$ relationship with participation in social security schemes. An increase in one unit of monthly income increased the probability of participation of informal sector workers in the formal social security schemes by $73.9 \%$. This is not surprising because income is one of the factors that influence informal sector workers participation in the formal social security schemes because enrollment to the scheme requires income and eligibility to receive benefits from the schemes depends on contributions made, which requires income as well. Thus, an increase in the monthly income increases the ability of the informal sector worker to enroll in the formal social security schemes. These findings are similar to earlier findings by Keizi (2006) in Rwanda, Adzawla et al. (2015) in Ghana and Agravat and Kaplelach (2017) in Kenya that increase in monthly income has positive influence on informal sector workers participation in the formal social security schemes. In Kenya, for instance, Agravat and Kaplelach (2017) reported a positive and significant correlation between level of income and micro-pension uptake. This means that any positive changes in level of income led to increased micro-pension uptake.

In addition, capital of the economic activity showed positive significant ( $p=$ 0.032 ) relationship with the participation of informal sector workers in the social security. It was established that an increase in one unit of capital increased the likelihood of participation of informal sector workers in the formal social security schemes by $68.3 \%$. In principle, capital is invested to produce profit, thus, an increase in capital of informal sector worker will increase the profit and income he/she generates. This enables the informal worker to afford to enroll in the formal social security schemes. These findings are similar to Adzawla et al. (2015) and Kayitare (2016)'s observations that capital has positive influence on 
informal sector workers participation in the formal social security schemes.

\section{Conclusion and Recommendations}

This study has examined the factors influencing informal sector worker's participation in the formal social security schemes in Dodoma City. It was found that food vending, cereal selling and petty businesses were the most common economic activities performed by the informal sector workers in the area. However, participation of these informal sector workers in the formal social security schemes was generally low as majority of them were not members of the formal social security schemes, but participated in other forms of social protection like SACCOS and VICOBA. The determinants of informal sector workers' participation in formal social security schemes were sex, nature of business, amount contributed, monthly income and capital of the economic activity. It is recommended that deliberate efforts should be put in place to educate informal sector workers on the importance of the social security schemes, including the benefits offered by the schemes. Similarly, social security schemes should set their monthly contribution rates at a level that is affordable to informal sector workers given their relatively low incomes, and design benefits packages that fit the need of the informal sector workers. A major limitation of this study is that it was conducted in only one city, covering two wards and a small sample of informal sector workers. Thus, the findings of this study should be seen as context specific since there could be many other factors influencing informal sector workers participation in formal social security schemes in other urban settings. Therefore, further research covering more urban areas should be conducted to clearly understand the phenomenon and draw conclusions and policy recommendations which can be generalizable across the country.

\section{Conflicts of Interest}

The authors declare no conflicts of interest regarding the publication of this paper.

\section{References}

Adzawla, W., Baanni, S. A., \& Wontumi, R. F. (2015). Factors Influencing Informal Sector Workers' Contribution to Pension Scheme in the Tamale Metropolis of Ghana. Journal of Asian Business Strategy, 5, 37-45.

Agravat, D. R., \& Kaplelach, S. (2017). Effect of Demographic Characteristics on Micro-Pension Uptake among Informal Employees of Kenya Ports Authority. Journal of Business and Strategic Management, 2, 95-117.

Dorfman, M. (2015). Pension Patterns in Sub-Saharan Africa. Social Protection and Labour Discussion Paper No. 1503, Washington DC: The World Bank.

Dungumaro, E. W. (2012). Social Protection in Tanzania. In T. Kalusopa, R. Dicks, \& C. Osei-Boateng (Eds.), Social Protection Schemes in Africa. Accra: African Labour Research Network (ALRN).

Holzmann, R., \& Jorgensen, S. (2000). Social Risk Management: A New Conceptual 
Framework for Social Protection and Beyond. World Bank Social Protection Discussion Paper Series No. 0006, Washington DC: The World Bank.

Hu, Y., \& Stewart, F. (2009). Pension Coverage and Informal Sector Workers: International Experiences. OECD Working Papers on Insurance and Private Pensions No. 31, OECD Publishing.

International Labour Organisation (ILO) (2002). Women and Men in the Informal Economy: A Statistical Picture. Employment Sector Paper, Geneva: International Labour Organisation.

International Labour Organisation (ILO) (2014). World Social Protection Report 2014/15: Building Economic Recovery, Inclusive Development and Social Justice. Geneva: International Labour Organisation.

International Labour Organisation (ILO) (2018). International Labour Standards on Social Security.

https://www.ilo.org/global/standards/subjects-covered-by-international-labour-standar ds/social-security/lang--en/index.htm

Kayitare, E. (2016). Factors Affecting Rwandan Informal Sectors Workers Participation in Public Pension Schemes. PhD Thesis, Minneapolis: Walden University.

Keizi, L. K. (2006). Barriers to Pension Scheme Participation by Workers in the Informal Economy. Research Paper, Retirement Benefits Authority, Research \& Policy Analysis Department.

Kothari, C. R., \& Garg, G. (2014). Research Methodology: Methods and Techniques. New Delhi: New Age International Publishers.

Kyengo, G. W. (2010). A Survey of Pension Coverage of Informal Sector Workers in Nairobi County. MBA Thesis, Nairobi: University of Nairobi.

Maduga, F. C. (2015). Public Communication and Social Security Delivery in Tanzania. PhD Thesis, London: University of West London.

Olivier, M., Malabo, J., \& Kalula, E. (2012). Informality, Employment and Social Protection: Some Critical Perspective for/from Developing Countries. Working Paper No. 9, Geneva: International Social Security Association.

Social Security Regulatory Authority (SSRA) (2013). Social Security Trend in Tanzania. Dar es Salaam: SSRA.

United Republic of Tanzania (URT) (2003). The National Social Security Policy. Dar es Salaam: Ministry of Labour, Youth Development and Sports. 